\title{
Variability of wave impact measurements on vertical breakwaters
}

\author{
Andrea Marzeddu , Tiago C. A. Oliveira, Francesc Xavier Gironella \& Agustin \\ Sánchez-Arcilla
}

To cite this article: Andrea Marzeddu, Tiago C. A. Oliveira , Francesc Xavier Gironella \& Agustin Sánchez-Arcilla (2017): Variability of wave impact measurements on vertical breakwaters, Journal of Hydraulic Research, DOI: 10.1080/00221686.2017.1312576

To link to this article: http://dx.doi.org/10.1080/00221686.2017.1312576

\section{曲 Published online: 19 Jun 2017.}

Submit your article to this journal $\pi$

ЏII Article views: 52

Q View related articles $\sqsubset$

View Crossmark data ¿ 
Research paper

\title{
Variability of wave impact measurements on vertical breakwaters
}

\author{
ANDREA MARZEDDU (D), Researcher, Laboratorio de Ingenieria Maritima (LIM), Universitat Politecnica de Catalunya, \\ Barcelona 08034, Spain \\ Email: andrea.marzeddu@upc.edu (author for correspondence)
}

TIAGO C. A. OLIVEIRA D, Research Fellow, Tropical Marine Science Institute, National University of Singapore, Singapore Email: tmscaot@nus.edu.sg

FRANCESC XAVIER GIRONELLA (D), I COBOS, Professor, Laboratorio de Ingenieria Maritima (LIM), Universitat Politecnica de Catalunya, Barcelona 08034, Spain

Email: xavi.gironella@upc.edu

AGUSTIN SÁNCHEZ-ARCILLA D, CONEJO (IAHR Member), Professor, Laboratorio de Ingenieria Maritima (LIM), Universitat Politecnica de Catalunya, Barcelona 08034, Spain

Email: agustin.arcilla@upc.edu

\begin{abstract}
The measurement of wave-induced impacts on structures involves significant scientific and engineering challenges. Regular nearly breaking pgbgand broken waves generated following cnoidal and first-order Stokes wavemaker theory have been considered to study the variability of wave impacts on vertical breakwaters. Four small-scale hydraulic experiments were carried out and repeated 120 times using high-speed pressure and force measurement equipment. High variability in the measured pressure field and total force were observed, reflecting the random nature of the studied phenomena. The force variability was similar for the nearly breaking and broken waves. The maximum measured force was between 166 and $177 \%$ of the minimum measured force. In relation to the force distribution and maximum pressure points, the observed variability is higher for broken waves. To deal with such variability in the observations, suitable probability distributions for forces $(G E V)$ and pressures $(G a m m a)$ are proposed.
\end{abstract}

Keywords: Impact loads; pressure/force measurements; test repeatability; vertical structures; wave impact; wave loads

\section{Introduction}

The continuous draft increase in big vessels implies the construction of harbour protection structures at deeper waters. At these depths, the amount of material needed for rubble mound breakwaters makes them less cost-effective than vertical structures. However, during severe storms, wave breaking often happens in front of vertical breakwaters. This is mainly due to the high reflection associated to vertical structures, which can induce very steep and plunging wave conditions in front of the structure. Oumeraci (1994) provided a comprehensive review of the most important historical failures of this type of structure, highlighting the impact induced by breaking clapotis as the main reason for failure. Large-scale hydraulic tests have been performed over the last 20 years, leading to different formulations that allow calculation of loads induced by wave breaking on vertical breakwaters (Allsop, Kortenhaus, Oumeraci, \& McConnell, 1999; Bullock, Obhrai, Peregrine, \& Bredmose, 2007; Cuomo, Allsop, Bruce, \& Pearson, 2010; Oumeraci et al., 2001). However, for impulsive loads on vertical breakwaters Takahashi's formula (Takahashi, 2002; Takahashi, Tanimoto, \& Shimosako, 1994), based on small-scale hydraulic experiments, is one of the most frequently used. Takahashi's formula introduces an impulsive pressure coefficient into the Goda formula (Goda, 1974, 1985), initially developed for quasi-static loads. Most equations for impulsive loads on vertical breakwaters are based on semi-empirical models calibrated with wave flume (small and large-scale) data and, in some cases, with prototype-measured data (Minikin, 1963). For a comprehensive hydraulic design of vertical breakwaters, the following wave

Received 5 August 2016; accepted 25 March 2017/Currently open for discussion. 
induced load-related variables should be considered: (i) maximum pressure; (ii) location of pressure maxima; and (iii) total force and its application point (overturning moment).

Vertical pressure distributions in hydraulic tests can be determined using the results from arrays of pressure transducers. The maximum pressure and its location can then be extracted from the pressure distribution diagram. During the design process, particular attention should be paid to where the structure joints are located (Cox \& Cooker, 2001), as they should not be placed close to the maximum pressure point. For the hydraulic design of a vertical breakwater, sliding and overturning are the primary failure modes (Goda, 1974) and are directly associated with force/pressure distribution. During hydraulic tests, the total force can be calculated from data obtained by load cells or by computing the integral of the vertical pressure distribution. The resulting force application point can be calculated by finding the mass centre of the vertical pressure distribution, experimentally determined if a combination of two (or more) load cells have been used for measuring the total force. Historically, in most of the wave impact physical tests, a vertical array of pressure transducers was installed on the seaward side of the structure (e.g. Bullock et al., 2007; Cuomo et al., 2010). Only a few experiments were performed using load cells for the direct measurement of the total force (e.g. Hofland, Lech Kaminski, \& Wolters, 2010). This is mainly due to the complexity, especially at large scale, of hanging large structures directly from the load cells.

The uncertainties regarding the measurements of pressures generated by impulsive wave conditions are very high (Bullock et al., 2007). Due to these uncertainties, generating correct measurements of wave impact loads on marine structures is probably one of the biggest challenges for coastal and maritime hydraulic modellers. Stagonas, Marzeddu, Gironella, and Sánchez-Arcilla (2016) performed a series of experiments to validate a pressure mapping system against classical measurements (pressure arrays and load cells). Their work showed that the spatial distribution of these impacts is characterized by pressure hot spots that appear slightly above the still water level (SWL). However, the horizontal position of the hot spots remains largely unpredictable (Bullock et al., 2007). The highly turbulent environment and the air/water mixture during wave breaking add further difficulty to the measurements. Furthermore, even if an almost perfect repeatability of the generated wave is guaranteed, this does not translate into perfect repeatability of the impact conditions (Stagonas et al., 2016).

The effects of sampling frequency on the measurement of wave induced impact loads poses another important problem (see e.g. Marzeddu, Gironella, Sachez-Arcilla, \& Sutherland, 2014). At higher sampling frequencies, the magnitude of the measured load peak can vary up to 10 times. Bullock et al. (2007) studied the scale and laboratory effects on wave induced impact loads. Using a Froude-scale model, a good agreement was found between prototype and model results. Furthermore, they illustrated the importance of having the same spatial and temporal resolution (laboratory tests were performed with lower spatial and temporal resolution) for a reliable comparison. According to Bullock et al. (2007), an unexpected behaviour of the measured loads at laboratory and prototype scales should not be excluded, due to the complex interactions occurring in the presence of air/water mixtures in a highly turbulent medium. A review of the literature on hydraulic tests dealing with waveinduced impact forces and pressures (Bullock et al., 2007; Marzeddu et al., 2014; Stagonas et al., 2016) revealed a limited understanding of the results variability, suggesting the need of a larger number of test repetitions for statistically robust and comparable datasets.

For most wave impact hydraulic tests, extreme long waves $(d / L<0.1$ and wave periods between 15 and $25 \mathrm{~s})$ in intermediate and shallow water-wave conditions need to be considered (Frostick, McLelland, \& Mercer, 2011; Hughes, 1993). Therefore, the accuracy of the laboratory results depends on how precisely such nonlinear waves are generated. In many wave-impact hydraulic studies (e.g. Marzeddu et al., 2014; Stagonas et al., 2016), waves are generated by piston or flap wavemakers moving according to the linear wave theory (Biésel \& Suquet, 1951). However, some studies (Goda, 1967, 1997; Morison, Crooke, \& Washington, 1953; Oliveira, SachezArcilla, Gironella, \& Madsen, 2017) reported the presence of secondary harmonic free waves for extreme long wave conditions, when the waves were generated by sinusoidally moving a paddle. To prevent the generation of unwanted secondary waves, various authors proposed different wavemaker theories based on second-order wave theory (Hudspeth \& Sulisz, 1991; Madsen, 1971; Schäffer, 1996), cnoidal wave theory (Goring, 1979), and stream function theory (Zhang \& Schäffer, 2007).

In this study, we aim to understand the effects of hydraulic test repeatability on the pressure and force on vertical breakwaters under regular wave-induced impact conditions. For this, nearly breaking and broken wave conditions generated by cnoidal and Stokes first-order wavemaker theory have been analysed and compared. Nearly breaking waves generate higher impact pressures/forces, this clearly being a condition to be taken into account for the design of vertical breakwaters. On the other hand, broken wave attacks cause highly turbulent environments (complicating the measurement conditions) and are a common situation in designing rigid structures in shallow waters. Unlike linear waves, cnoidal waves represent relatively long waves in intermediate and shallow waters. Both types of wave theories are applied in this study to evaluate the laboratory effects on wave generation. Four different small-scale experiments have been carried out and repeated 120 times. High-speed recordings with load cells and pressure transducers are used in all the test runs.

This paper is divided into five sections. In Section 2 we present the set-up of the small-scale hydraulic tests. Results of the loads induced by nearly breaking and broken waves, as generated by cnoidal and Stokes first-order wavemaker theories, are described in Section 3. The discussion is in Section 4 and conclusions are in Section 5. 


\section{Physical model tests}

\subsection{Experimental layout}

The experiments were carried out in the CIEMito wave flume at the Laboratori d'Enginyeria Maritima (LIM) of the Universitat Politecnica de Catalunya (LIM-UPC BarcelonaTech). The flume is $18 \mathrm{~m}$ long, $0.38 \mathrm{~m}$ wide, and $0.56 \mathrm{~m}$ deep; it is equipped with a piston type wave paddle that creates regular and irregular waves and a pumping system for currents. During the experiments, only $13.3 \mathrm{~m}$ of the flume was used and a vertical seawall model was placed at the end of a 1:15 smooth slope (Fig. 1). The water level was kept constant in all the experiments with a water depth of $0.285 \mathrm{~m}$ in front of the wave paddle and $0.115 \mathrm{~m}$ in front of the vertical wall. Figure 1a and 1c show the experimental layout for nearly breaking wave conditions. A $0.2 \times 0.38 \times 0.05 \mathrm{~m}$ (length $\times$ width $\times$ height $)$ block was placed at $0.5 \mathrm{~m}$ from the vertical wall to induce broken wave conditions (Fig. 1b and 1d).

\subsection{Wave generation}

Two types of regular waves were generated. The first type was based on cnoidal wavemaker theory (Goring, 1979), while for the second type, Stokes first-order wave generation (Biésel \& Suquet, 1951) was used. According to Goring (1979), the piston paddle displacement to generate a free surface cnoidal wave, $X_{c}$, can be represented as:

$$
X_{c}(t)=L\left(\frac{t}{T}-\frac{\theta_{c}}{2 K(m)}\right)
$$

where:

$$
\theta_{c}=2 K(w)\left(\frac{t}{T}-\frac{X_{c}}{L}\right)
$$

and $L$ is the wave length, $t$ is time, $T$ is the wave period, and $K(w)$ is the complete elliptic integral of the first kind and $w=H L^{2} / h^{3}$ is the elliptic parameter.

A Stokes first-order wave (linear wave) can be generated by a piston paddle displacement, $X_{l}$, as proposed by Biésel and Suquet (1951):

$$
X_{l}(t)=2 a\left(\frac{\sinh (2 k h)+2 k h}{8 \sinh ^{2}(k h)}\right) \sin (\omega t)
$$

where $a$ is the wave amplitude, $h$ is the water depth in front of the paddle, $k$ is the wave number $(k=2 \pi / L)$, and $\omega$ is the angular frequency $(\omega=2 \pi / T)$.

For each type of regular wave, a train of three waves was generated. The first and third waves (ramp-up and ramp-down waves) were always smaller than the second wave (target wave height). The ramp-up wave was fully reflected by the structure, while the second wave resulted in an impact on the wall. Each wave train was repeated 120 times for each generation type (cnoidal and linear) and each impact condition (nearly breaking and broken waves), adding up to a total of 480 independent wave tests. Because the first wave of the train was always reflected by the structure, the impact of the second wave was considered the "cleanest" and most repeatable. The analysed wave could be considered as representative of an extreme wave in an irregular wave train. Thus, only the force/pressures induced by the impact of this wave were considered in the analysis.

\subsection{Measurements}

Eight resistance wave gauges were used for measuring the free surface evolution at 3.00, 5.00, 5.08, 5.20, 5.60, 10.50, 10.71 , and $11.11 \mathrm{~m}$ from the wavemaker. A sampling rate of $100 \mathrm{~Hz}$ was used; the degree of accuracy of these sensors is (a)

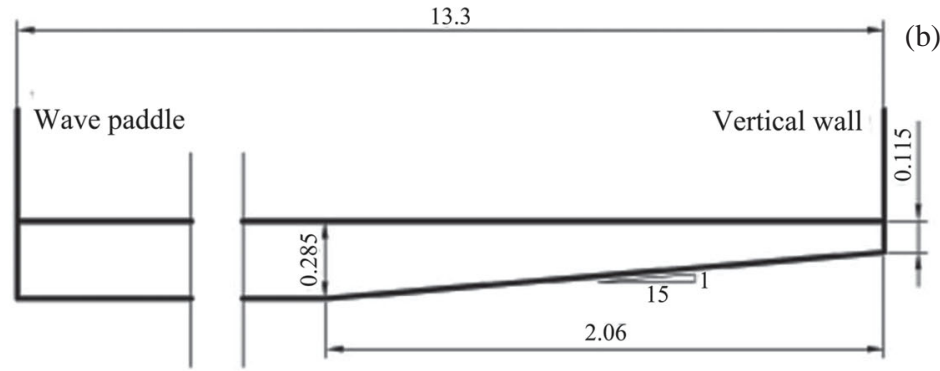

(b)

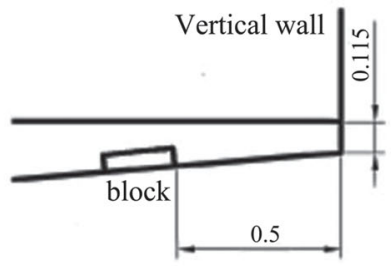

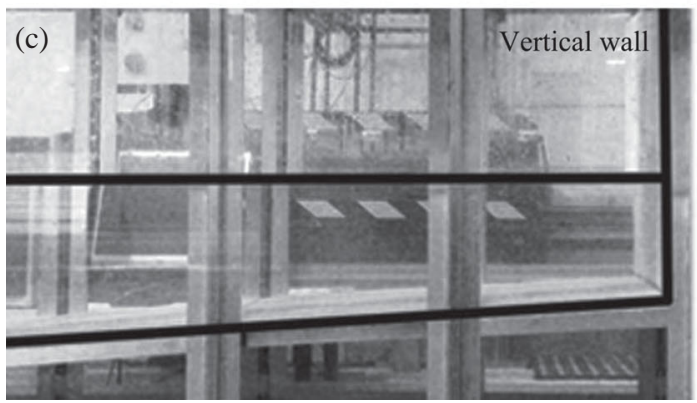

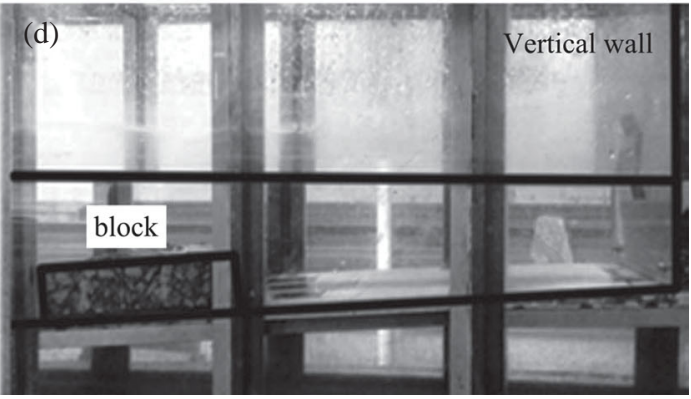

Figure 1 Experimental layout for nearly breaking wave attacks (a and c) and broken wave attacks (b and d). A $0.2 \mathrm{~m}$ length rectangular box was placed at $0.5 \mathrm{~m}$ from the vertical wall to induce broken waves onto the structure; all values in this figure are given in meter $(\mathrm{m})$ unit 
(a)

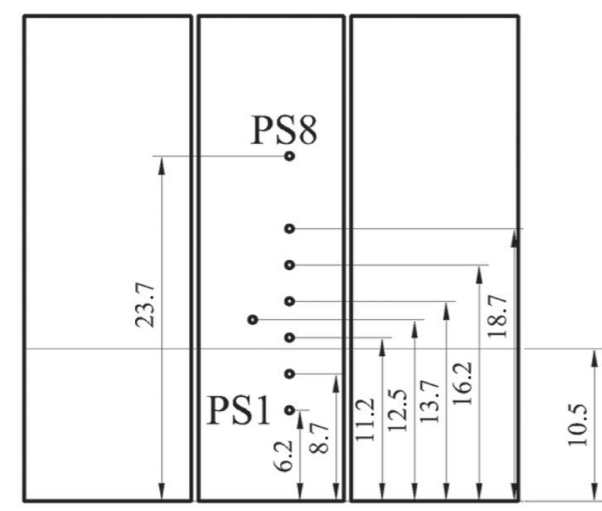

(b)

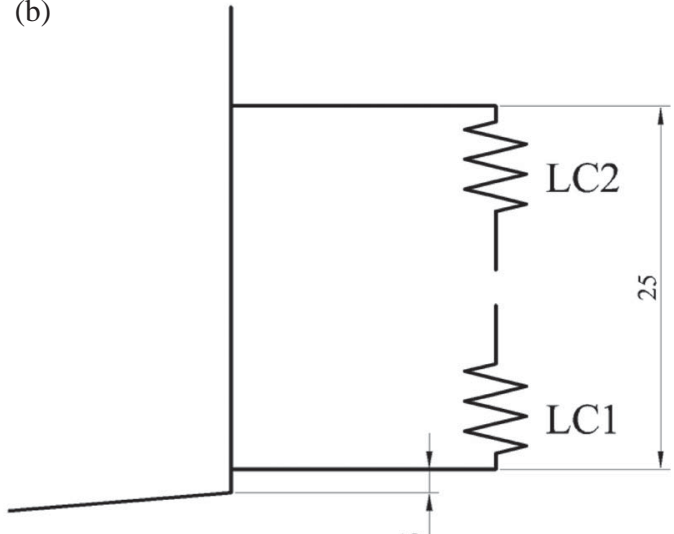

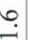
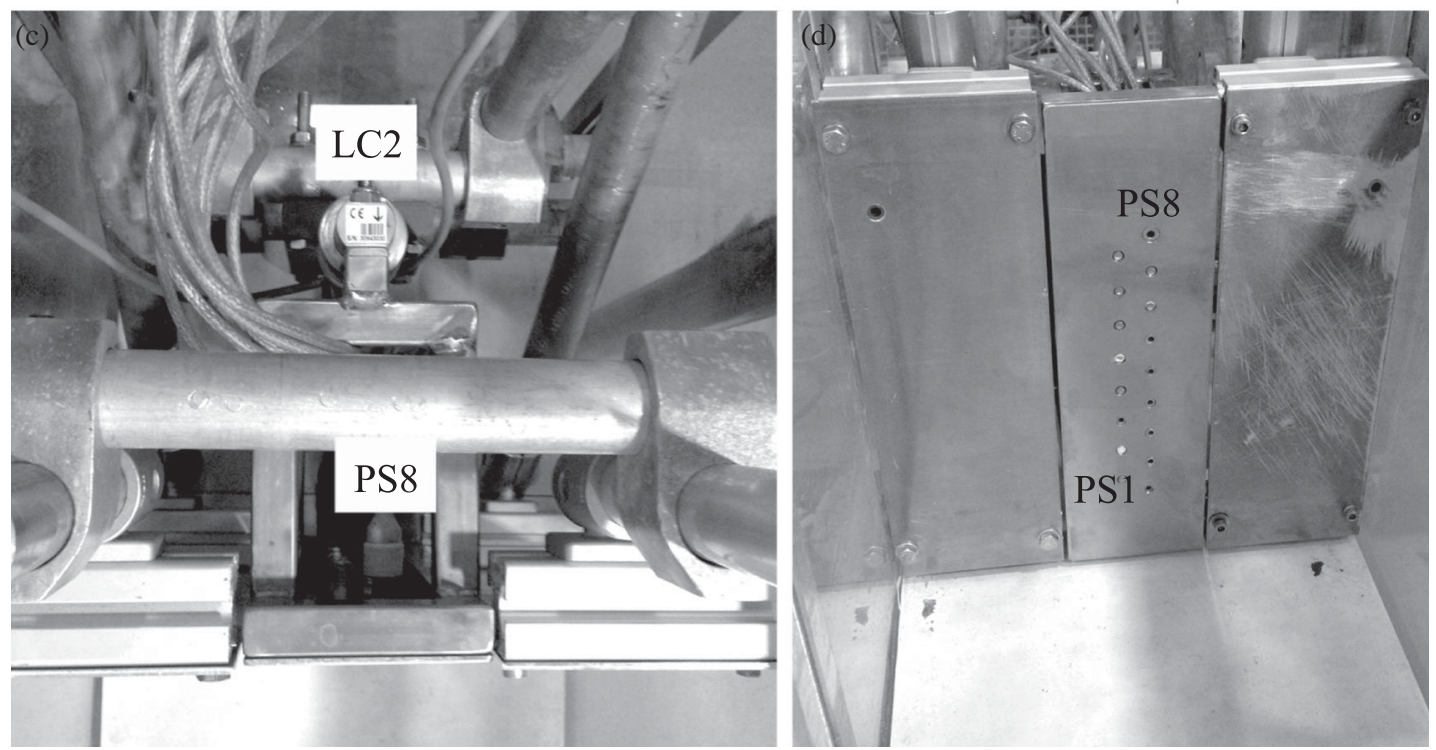

Figure 2 Experimental arrangement: (a) schematic frontal view of the wall showing the transducers (PS1-PS8); (b) schematic lateral view showing load cells (LC1-LC2); (c) top view photo of the instrumented vertical wall (d) front view photo of the vertical wall. All values in this figure are given in centimeter $(\mathrm{cm})$ unit

approximately $0.001 \mathrm{~m}$ (Oliveira, Sanchez-Arcilla, \& Gironella, 2012; Stagonas et al., 2016). The experimental arrangement consisted of an array of eight HBM P8AP pressure transducers (Hottinger Baldwin Messtechnik GmbH, Darmstadt, Germany) placed in the middle of the vertical wall. The vertical distances between the transducers (PS1 to PS3 and PS5 to PS8) are shown in Fig. 2a while an additional transducer PS4 was placed near the SWL and at a horizontal distance of $2.5 \mathrm{~cm}$ to the left of the array. The array was mounted on a segment of the wall $(35 \times 10$ $\mathrm{cm}$ ) and supported by two load cells, LC1 and LC2 (Fig. 2b).

The force/pressure measurement systems were the same as those used by Marzeddu et al. (2014), Marzeddu, Gironella, and Sánchez-Arcilla (2013) and Stagonas et al. (2016). Marzeddu et al. (2013) carried out tests with non-impulsive conditions to evaluate the capability of P8AP and Z6FC3 sensors to record repeatable loads. Results showed a satisfactory repeatability of the measured loads with a root mean square error of $5 \mathrm{~N} \mathrm{~m}^{-1}$, compared to normal range value of $150 \mathrm{~N} \mathrm{~m}^{-1}(3 \%)$.

The HBM P8AP is an absolute pressure transducer for measuring static and dynamic liquid or gas induced pressures that can be safely immersed in depths of up to $1 \mathrm{~m}$. Each transducer is composed of a strain-gauge sensor and is provided already calibrated (by HBM), holding an EC declaration of conformity and a test certificate. The maximum measuring range of the P8AP sensors used for this study was $103 \mathrm{kN} \mathrm{m}^{-2}$, with a reported accuracy of $0.3 \%$ of the maximum load, a 24 bit resolution and a natural frequency of the diaphragm of $12 \mathrm{kHz}$.

Force measurements were conducted using two Z6FC3 bending beam load cells (LC1-LC2 in Fig. 2b) with a nominal load of $50 \mathrm{~kg}$, an accuracy of $0.009 \%$ of the maximum load and a 24-bit resolution. Similarly to pressure transducers, load cells were calibrated and could be immersed to a maximum depth of $1 \mathrm{~m}$. An HBM QuantumX data acquisition system (Hottinger Baldwin Messtechnik $\mathrm{GmbH}$ ) was used to simultaneously obtain samples from each load cell and pressure transducer at a sampling frequency of $4.8 \mathrm{kHz}$. However, the system could be amplified and sample up to 16 channels with a maximum sampling rate of $19.2 \mathrm{kHz}$. For experiments with pressure transducers, (Marzeddu et al., 2013, 
2014) concluded that a satisfactory description of the pressure pulse can be obtained with a sampling frequency higher than $2.4 \mathrm{kHz}$.

\section{Results}

\subsection{Wave height}

Table 1 summarizes wave characteristics at $3 \mathrm{~m}$ from the paddle for cnoidal and linear waves. The values correspond to the second wave in the wave train (wave highlighted in Fig. 3a), representing nearly breaking and broken waves. The repeatability of the generated waves was tested; the root mean square error $\left(E_{R M S E}\right)$ and percentage error (computed on wave height) are shown in Table 1. The target wave height and period were $H=0.16 \mathrm{~m}$ and $T=2.3 \mathrm{~s}$ respectively. At a water depth of $0.285 \mathrm{~m}$, the target wave presented a large Ursell number $(U r=94.95)$ and low relative water depth $(h / L=0.08)$, indicating highly nonlinear wave characteristics with corresponding implication for their evolution (Oliveira, Gironella, SanchezArcilla, Sierra, \& Celigueta, 2009; Oliveira et al., 2017). The wave periods of the generated cnoidal and linear waves matched the target period perfectly. The generated wave height was 0.120 and $0.155 \mathrm{~m}$ for cnoidal and linear waves, respectively. These differences between target and generated wave height can be due in part to the leakage around the paddle, which can decrease

Table 1 Incoming wave parameters, $E_{R M S E}$, and percentage of error on surface elevation measurements for 120 waves from each category. Wave characteristics and wave height error calculation were computed from wave probe number 1 at $3 \mathrm{~m}$ from the wave paddle

\begin{tabular}{|c|c|c|c|c|c|c|c|c|c|c|}
\hline & \multirow[b]{2}{*}{$H(\mathrm{~m})$} & \multirow[b]{2}{*}{$T(\mathrm{~s})$} & \multirow[b]{2}{*}{$d(\mathrm{~m})$} & \multirow[b]{2}{*}{$\mathrm{N}^{\circ}$ rep. } & \multirow[b]{2}{*}{ Ur } & \multirow[b]{2}{*}{$d / L$} & \multicolumn{2}{|c|}{$E_{R M S E}(\mathrm{~m})$} & \multicolumn{2}{|c|}{ Error (\%) } \\
\hline & & & & & & & Max & Mean & Max & Mean \\
\hline Target & 0.160 & 2.3 & 0.285 & 120 & 95.0 & 0.08 & & & & \\
\hline Cnoidal & 0.120 & 2.3 & 0.285 & 120 & 71.2 & 0.08 & 0.0035 & 0.0011 & 2.9 & 1.0 \\
\hline Linear & 0.155 & 2.3 & 0.285 & 120 & 92.0 & 0.08 & 0.0021 & $6.4 \mathrm{e}-4$ & 1.3 & 0.4 \\
\hline
\end{tabular}
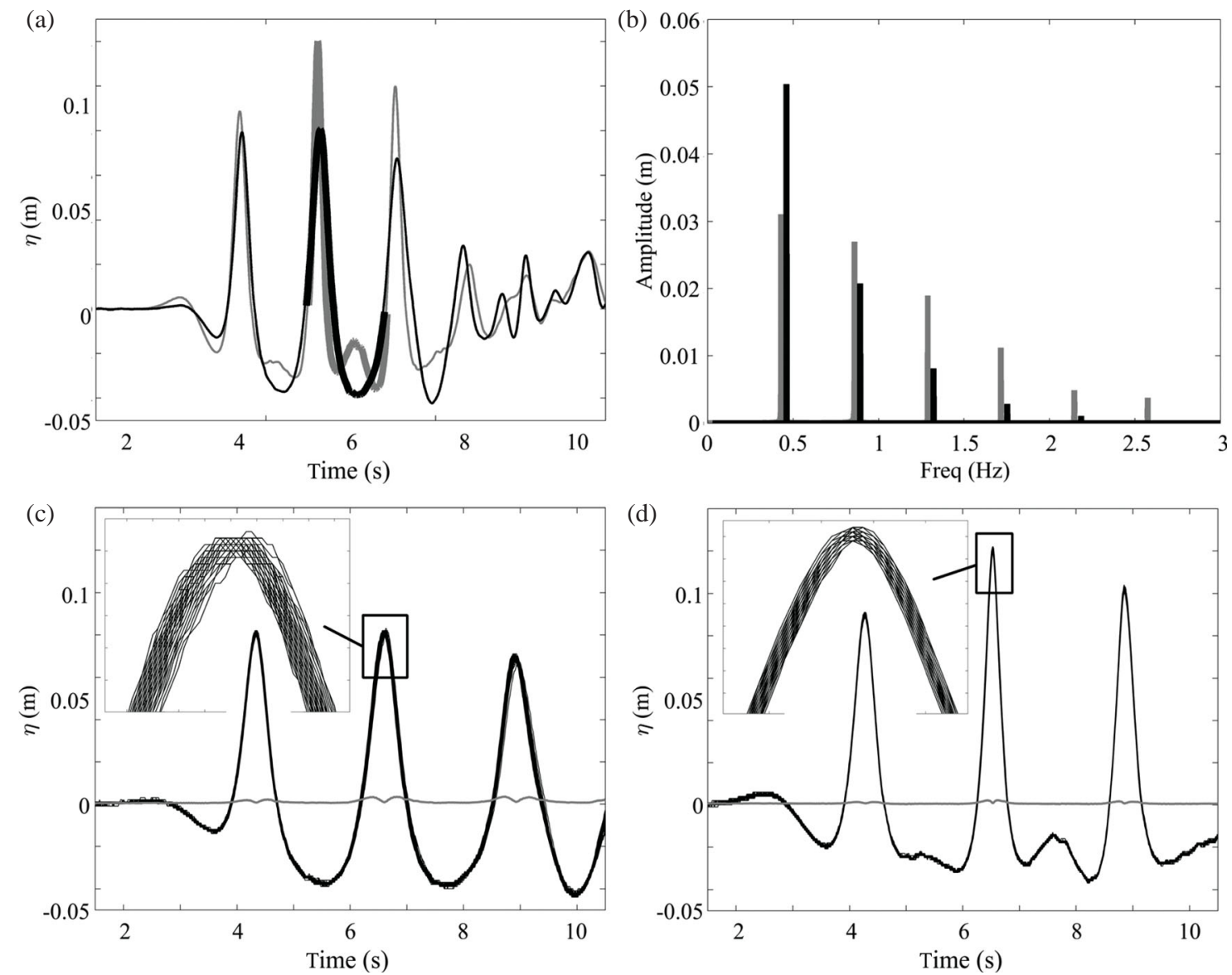

Figure 3 (a) Free surface evolution and selection of the analysed wave using the zero-crossing (zero-up) technique. (b) Amplitude spectrum (the frequencies for the cnoidal generation have been moved slightly forward in order to avoid overlap and make the figure clearer). Black and grey lines represent the results obtained with cnoidal and linear wave generation, respectively. (c) and (d) show for cnoidal and linear wave generation, respectively, the free surface evolution, $\eta_{i}$, of all 120 test repetitions (black lines) and the corresponding $E_{R M S E}$ (grey line) 
Table 2 Amplitudes (m) and energy $\left(\mathrm{m}^{2} \mathrm{~s}^{2}\right)$ calculated as the integral of the spectrums of the two types of wave attacks. Different intervals for the integral calculation were used in order to calculate the energy associated at each sub-harmonic

\begin{tabular}{llcccl}
\hline & & & & & \multicolumn{1}{c}{ Total } \\
& & $0.43 \mathrm{~Hz}$ & $0.86 \mathrm{~Hz}$ & $1.29 \mathrm{~Hz}$ & spectrum \\
\hline Cnoidal & Energy $\left(\mathrm{m}^{2} \mathrm{~s}^{2}\right)$ & $8.6 \mathrm{e}-04$ & $1.38 \mathrm{e}-04$ & $2.21 \mathrm{e}-05$ & 0.00103 \\
& Amplitude $(\mathrm{m})$ & 0.050 & 0.021 & 0.008 & 0.06 \\
Linear & Energy $\left(\mathrm{m}^{2} \mathrm{~s}^{2}\right)$ & $5.65 \mathrm{e}-04$ & $3.54 \mathrm{e}-04$ & $1.04 \mathrm{e}-04$ & 0.00106 \\
& Amplitude $(\mathrm{m})$ & 0.031 & 0.027 & 0.019 & 0.076 \\
\hline
\end{tabular}

the amplitude of a generated wave (Hughes, 1993; Madsen, 1971). Wave heights in Table 1 were calculated as the difference between the maximum (wave crest) and the minimum (wave trough) free surface level. Regarding $E_{R M S E}$ and error, hardly any variations were determined due to test repeatability (Table 1).

For each time instant, $t$, the $E_{R M S E}$ was calculated using:

$$
E_{R M S E}(t)=\sqrt{\frac{\sum_{i=1}^{n}\left(\eta_{i}(t)-\bar{\eta}(t)\right)^{2}}{n}}
$$

where $\eta_{i}(t)$ is the value of the free surface for repetition $i$ at time instant $t, \bar{\eta}(t)$ is the average free surface at time instant $t$, and $n=120$ is the total number of repetitions.

In Fig. $3 \mathrm{c}$ and $3 \mathrm{~d}$ all the $120 \eta_{i}$ time series and $E_{R M S E}$ are plotted from $t=1.5$ to $t=10.5$ for cnoidal and linear waves, respectively.

The error is defined for each time instant by:

$$
\operatorname{error}(t)=\frac{E_{R M S E}(t)}{H_{\eta}}
$$

where $H_{\eta}=\left(\eta_{\max }-\eta_{\min }\right)$ is calculated for the second wave of the train (target wave).

Figure 3a shows the differences between the free surface evolution at $3 \mathrm{~m}$ from the wave paddle obtained with cnoidal and Stokes first-order wavemaker theory. An unwanted free harmonic can be observed in the case of linear waves (two distinct waves can be seen in the trough area). The amplitude spectra of cnoidal and linear waves are shown in Fig. 3b. Table 2 summarizes the energy and amplitude for the first three harmonics. Although the total energy is similar in both types of generated waves, there are significant differences in energy distribution through the harmonics. The cnoidal wave height calculated as $H_{\eta}$, is similar to the cnoidal height approximation calculated as $H_{a}=2 a_{1}$. The values are 0.120 and $0.100 \mathrm{~m}$, respectively, with $\eta$ the surface elevation and $a_{1}$ the amplitude of the first harmonic. However, a huge difference was found for $H_{\eta}$ and $H_{a}$ for the linear waves: 0.155 and $0.062 \mathrm{~m}$, respectively. This difference is due to the presence of undesired free harmonics, with amplitudes of the same order of magnitude as the first harmonic, (Madsen, 1971) in linear waves.

A graphic summary of the time history of nearly breaking and broken waves colliding directly with a vertical wall in a cnoidal wave test is shown in Fig. 4.

\subsection{Nearly breaking wave attack loads}

Figure 5 shows the vertical pressure distributions induced by the two types of generated waves for nearly breaking conditions. Dimensional (Fig. 5a) and dimensionless results (Fig. 5b and $5 \mathrm{c}$ ) were considered. The maximum pressure in cnoidal waves was always recorded at PS5 or PS6, placed at +0.025 and $+0.051 \mathrm{~m}$ above the SWL, respectively. In PS6, where maximum pressure was recorded in $86 \%$ of the repetitions, the ratio between the maximum and minimum pressure was $482 \%$,
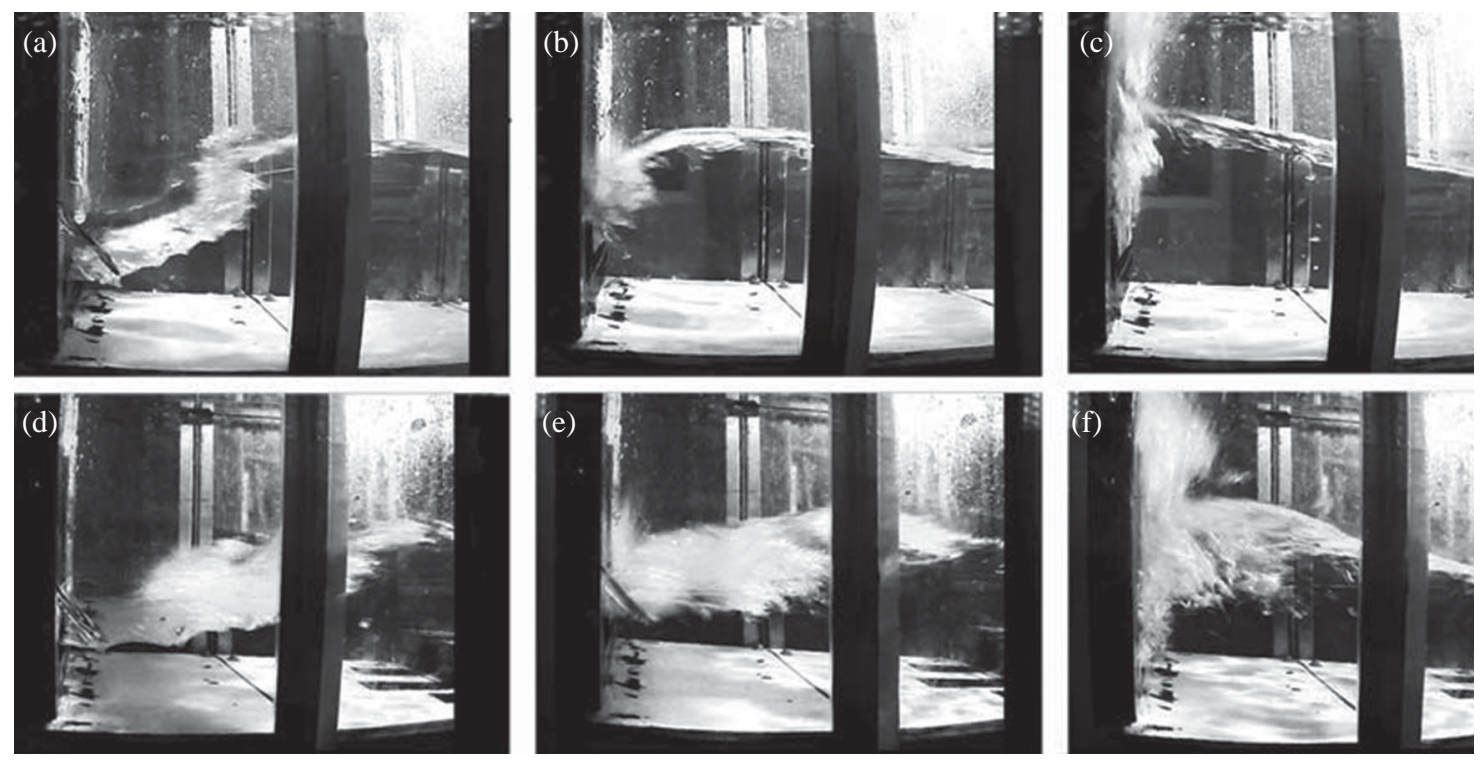

Figure 4 Snapshot time history of nearly breaking (top) and broken (bottom) waves impacting directly onto a vertical wall. A cnoidal wave case is seen in the photographs 

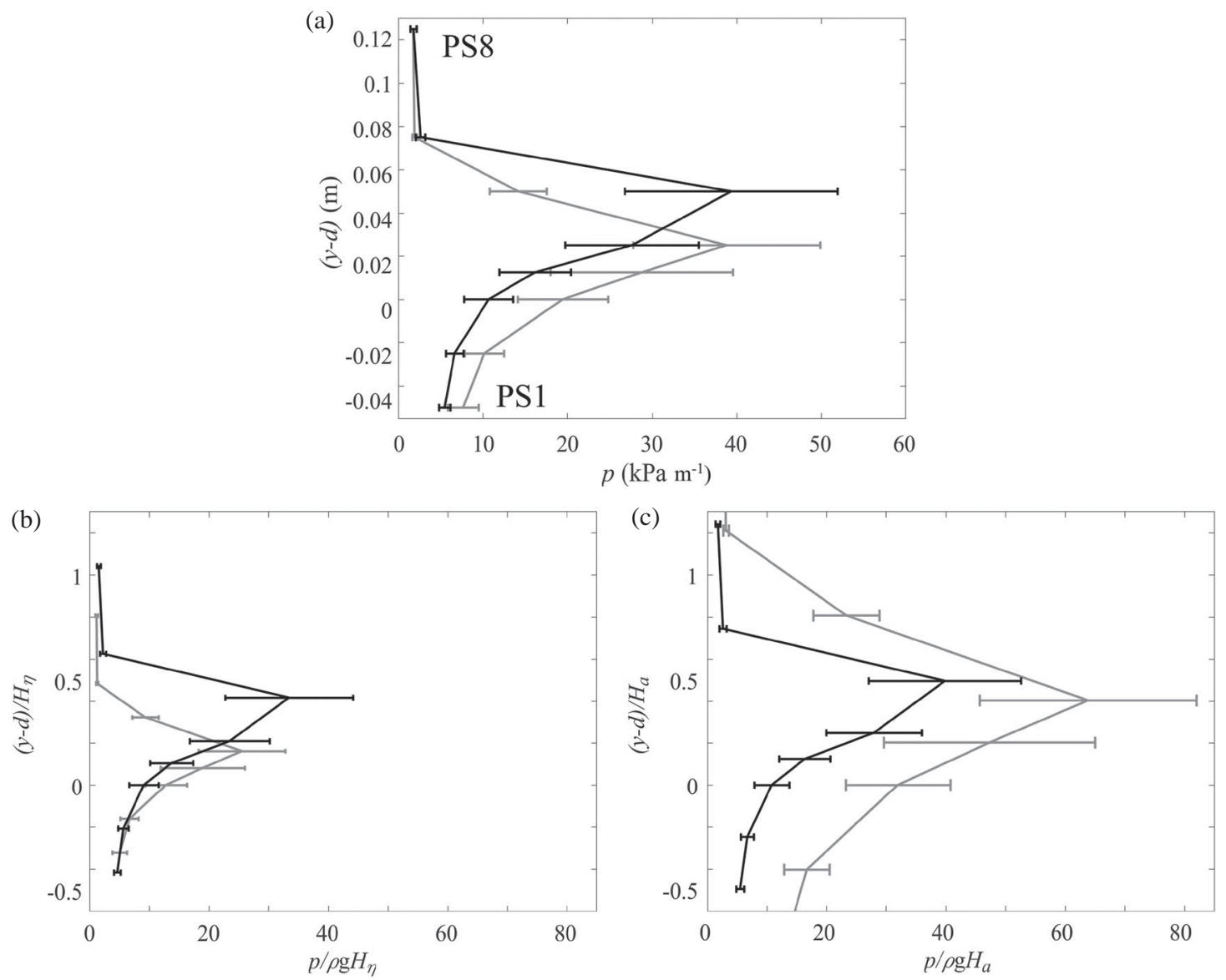

Figure 5 Comparison of vertical pressure distribution (means and standard deviations). Cnoidal (black) and linear (grey) wave generation theories: (a) dimensional plot; (b) dimensionless plot in relation to $H_{\eta}$; (c) dimensionless plot in relation to $H_{a}$. Nearly breaking wave attack conditions

and the maximum/mean pressure ratio was $209 \%$. For linear waves, the maximum pressure was always recorded at PS4 or PS5, placed at +0.125 and $+0.025 \mathrm{~m}$ above the SWL, respectively. In PS5, where the maximum was recorded in $78 \%$ of the repetitions, the maximum/minimum pressure ratio was $419 \%$, and the maximum/mean pressure ratio was $178 \%$.

The dimensionless pressures were calculated by dividing the recorded pressure by $\rho g H$, where $\rho$ is the water density and $g$ is the acceleration due to gravity. Both $H_{\eta}$ and $H_{a}$ are used in the dimensionless analysis. The relative vertical position $(y-$ d) $/ H$ was selected as a dimensionless parameter, where $y$ is the distance to the bottom and $d$ the water depth at the toe of the structure. For both maximum pressures and forces a number of parametric distributions have been tested (for both nearly breaking and broken waves) to find the best fit for the studied datasets. The selection of the "best distribution" has been done using a Bayesian information criterion (BIC). A chi-squared test has been performed to evaluate the goodness of fit of the "best distribution". All the observed populations accept the null hypothesis (the observed sample proportions are equal to those expected with a significance level of 0.05$)$. The scores ( $p$-values) of the chi-square test are reported in Tables 3-6.

The Gamma distribution probability density function presents the best fit for the maximum pressure recorded by PS6 in cnoidal waves and by PS5 in linear waves:

$$
q_{p}=\frac{1}{b^{s} \Gamma(z)} p^{s-1} e^{-p / b}
$$

where $q_{p}$ is the probability density function, $p$ is the maximum pressure, $s$ is the shape parameter and $b$ is the scale parameter. The results and Gamma distribution parameters for the pressures induced by nearly breaking waves are summarized in Table 3. The statistical distribution of the pressures, recorded by the sensors with the higher probability to record the maximum pressures (PS6 for the cnoidal and PS5 for the linear), with the Gamma distribution and the histograms of the two datasets are presented in Fig. 6.

Figure 7 shows the statistical distribution of the total force measured for the dimensional (Fig. 7a) and dimensionless (Fig. $7 \mathrm{~b}$ and $7 \mathrm{c}$ ) analyses. A GEV distribution was fitted and the histograms of the two sets of data are presented in the figure. In the case of cnoidal waves, the variability found for pressure was also observed for the force and the force application point. The maximum force was $168 \%$ of the minimum force and $133 \%$ of the most probable force value. For linear waves, similar ratios were determined, with a maximum recorded force $174 \%$ of the minimum and $138 \%$ of the most probable force value. 
Table 3 Summary of the maximum pressure recorded for nearly breaking wave attack conditions

\begin{tabular}{|c|c|c|c|c|c|c|c|c|c|c|c|c|}
\hline & & \multicolumn{4}{|c|}{ Maximum pressure } & & & & & & & \\
\hline & & \multicolumn{3}{|c|}{ Position } & \multirow[t]{2}{*}{ Statistics } & \multicolumn{4}{|c|}{ Recorded pressures } & \multicolumn{3}{|c|}{ PDF Gamma distribution } \\
\hline & & Symbol & PS & Value & & Symbol & Max & Min & Mean \pm SD & $s$ & $b$ & $p$-value \\
\hline \multirow[t]{3}{*}{ Cnoidal } & Dimensional & $y-d(\mathrm{~m})$ & PS6 & 0.051 & $\begin{array}{l}\text { PS5 } 14 \% \\
\text { PS6 } 86 \%\end{array}$ & $P\left(\mathrm{kPa} \mathrm{m}^{-1}\right)$ & 82 & 17 & $39.4 \pm 12.6$ & 10.1 & 3.9 & 0.9 \\
\hline & Dimensionless $H_{\eta}$ & $\frac{y-d}{H_{\eta}}$ & & 0.42 & & $\frac{p}{\rho g H_{\eta}}$ & 70 & 14 & $33.4 \pm 10.7$ & & 3.3 & \\
\hline & Dimensionless $H_{a}$ & $\frac{y-d}{H_{a}}$ & & 0.49 & & $\frac{p}{\rho g H_{a}}$ & 83 & 17 & $39.8 \pm 12.7$ & & 3.9 & \\
\hline \multirow[t]{3}{*}{ Linear } & Dimensional & $y-d(\mathrm{~m})$ & PS5 & 0.025 & PS4 22\% & $P\left(\mathrm{kPa} \mathrm{m}^{-1}\right)$ & 69 & 16 & $38.8 \pm 11.1$ & 12 & 3.23 & 0.92 \\
\hline & Dimensionless $H_{\eta}$ & $\frac{y-d}{H_{\eta}}$ & & 0.16 & PS5 78\% & $\frac{p}{\rho g H_{\eta}}$ & 45 & 11 & $25.5 \pm 7.3$ & & 2.13 & \\
\hline & Dimensionless $H_{a}$ & $\frac{y-d}{H_{a}}$ & & 0.4 & & $\frac{p}{\rho g H_{a}}$ & 114 & 27 & $63.8 \pm 18.2$ & & 5.32 & \\
\hline
\end{tabular}

Table 4 Summary of the maximum force recorded in the case of nearly breaking wave attack conditions

\begin{tabular}{|c|c|c|c|c|c|c|c|c|c|c|c|c|c|}
\hline & & \multicolumn{4}{|c|}{ Application point position } & \multicolumn{4}{|c|}{ Recorded force } & \multicolumn{4}{|c|}{ PDF $G E V$ distribution } \\
\hline & & Symbol & Max & Min & $\overline{\text { Mean }}$ & Symbol & Max & Min & Mode & $r$ & $\sigma$ & $\mu$ & $\overline{p \text {-value }}$ \\
\hline \multirow[t]{3}{*}{ Cnoidal } & Dimensional & $y-d(\mathrm{~m})$ & 0.034 & 0.02 & 0.03 & $F\left(\mathrm{Nm}^{-1}\right)$ & 2210 & 1311 & 1662 & -0.214 & 160 & 1626 & 0.09 \\
\hline & Dimensionless $H_{\eta}$ & $\frac{y-d}{H_{\eta}}$ & 0.28 & 0.17 & 0.25 & $\frac{F}{\rho g H_{\eta} d}$ & 16 & 10 & 12 & & 1.182 & 12.009 & \\
\hline & Dimensionless $H_{a}$ & $\frac{y-d}{H_{a}}$ & 0.34 & 0.2 & 0.3 & $\frac{F}{\rho g H_{a} d}$ & 19 & 12 & 15 & & 1.407 & 14.296 & \\
\hline \multirow[t]{3}{*}{ Linear } & Dimensional & $y-d(\mathrm{~m})$ & 0.023 & 0.01 & 0.02 & $F\left(\mathrm{Nm}^{-1}\right)$ & 1885 & 1082 & 1367 & -0.061 & 169 & 1350 & 0.25 \\
\hline & Dimensionless $H_{\eta}$ & $\frac{y-d}{H_{\eta}}$ & 0.15 & 0.06 & 0.11 & $\frac{F}{\rho g H_{\eta} d}$ & 11 & 6 & 8 & & 0.934 & 7.723 & \\
\hline & Dimensionless $H_{a}$ & $\frac{y-d}{H_{a}}$ & 0.23 & 0.1 & 0.17 & $\frac{F}{\rho g H_{a} d}$ & 27 & 15 & 20 & & 2.334 & 19.31 & \\
\hline
\end{tabular}

Table 5 Summary of the maximum pressure recorded for broken wave conditions

\begin{tabular}{|c|c|c|c|c|c|c|c|c|c|c|c|c|}
\hline & & \multicolumn{4}{|c|}{ Maximum pressure } & & & & & & & \\
\hline & & \multicolumn{3}{|c|}{ Position } & \multirow[t]{2}{*}{ Statistics } & \multicolumn{4}{|c|}{ Recorded pressures } & \multicolumn{3}{|c|}{$\begin{array}{c}\text { PDF Gamma } \\
\text { distribution }\end{array}$} \\
\hline & & Symbol & PS & Value & & Symbol & Max & Min & Mean \pm SD & $s$ & $b$ & $p$-value \\
\hline \multirow[t]{3}{*}{ Cnoidal } & Dimensional & $y-d(\mathrm{~m})$ & PS2 & -0.025 & $\begin{array}{l}\text { PS2 42\% } \\
\text { PS3 38\% }\end{array}$ & $\begin{array}{l}p \\
\left(\mathrm{kPa} \mathrm{m}^{-1}\right)\end{array}$ & 26 & 4 & $8.2 \pm 3.2$ & 8.47 & 0.968 & 0.47 \\
\hline & Dimensionless $H_{\eta}$ & $\frac{y-d}{H_{\eta}}$ & & -0.17 & $\begin{array}{l}\text { PS4 } 15 \% \\
\text { PS5 5\% }\end{array}$ & $\frac{p}{\rho g H_{\eta}}$ & 22 & 3.4 & $7 \pm 2.7$ & & 0.822 & \\
\hline & Dimensionless $H_{a}$ & $\frac{y-d}{H_{a}}$ & & -0.25 & $\begin{array}{l}\text { PS1.1\% } \\
\text { PS2 34\% }\end{array}$ & $\frac{p}{\rho g H_{a}}$ & 26 & 4 & $8.3 \pm 3.2$ & & 0.979 & \\
\hline \multirow[t]{3}{*}{ Linear } & Dimensional & $y-d(\mathrm{~m})$ & PS2 & 0 & $\begin{array}{l}\text { PS3 20\% } \\
\text { PS4 28\% }\end{array}$ & $\begin{array}{l}p: \\
\left(\mathrm{kPa} \mathrm{m}^{-1}\right)\end{array}$ & 26 & 4 & $8.2 \pm 3.2$ & 11.03 & 0.502 & 0.07 \\
\hline & Dimensionless $H_{\eta}$ & $\frac{y-d}{H_{\eta}}$ & & 0 & PS5 13\% & $\frac{p}{\rho g H_{\eta}}$ & 22 & 3.4 & $7 \pm 2.7$ & & 0.33 & \\
\hline & Dimensionless $H_{a}$ & $\frac{y-d}{H_{a}}$ & & 0 & PS6 4\% & $\frac{p}{\rho g H_{a}}$ & 26 & 4 & $8.3 \pm 3.2$ & & 0.826 & \\
\hline
\end{tabular}


Table 6 Summary of the maximum force recorded for broken wave conditions

\begin{tabular}{|c|c|c|c|c|c|c|c|c|c|c|c|c|c|}
\hline & & \multicolumn{4}{|c|}{ Application point position } & \multicolumn{4}{|c|}{ Recorded force } & \multicolumn{4}{|c|}{ PDF $G E V$ distribution } \\
\hline & & Symbol & Max & Min & Mean & Symbol & Max & Min & Mode & $r$ & $\sigma$ & $\mu$ & $p$-value \\
\hline \multirow[t]{3}{*}{ Cnoidal } & Dimensional & $y-d(\mathrm{~m})$ & 0.02 & -0.014 & 0.007 & $F\left(\mathrm{Nm}^{-1}\right)$ & 442 & 267 & 315 & -0.063 & 28 & 312 & 0.17 \\
\hline & Dimensionless $H_{\eta}$ & $\frac{y-d}{H_{\eta}}$ & 0.18 & -0.12 & 0.06 & $\frac{F}{\rho g H_{\eta} d}$ & 3.3 & 2.0 & 2.3 & N/A & 0.21 & 2.31 & $\mathrm{~N} / \mathrm{A}$ \\
\hline & Dimensionless $H_{a}$ & $\frac{y-d}{H_{a}}$ & 0.20 & -0.14 & 0.07 & $\frac{F}{\rho g H_{a} d}$ & 3.9 & 2.3 & 2.8 & N/A & 0.25 & 2.75 & N/A \\
\hline \multirow[t]{3}{*}{ Linear } & Dimensional & $y-d(\mathrm{~m})$ & 0.19 & -0.04 & 0.08 & $F\left(\mathrm{Nm}^{-1}\right)$ & 380 & 215 & 278 & -0.135 & 26 & 274 & 0.15 \\
\hline & Dimensionless $H_{\eta}$ & $\frac{y-d}{H_{\eta}}$ & 1.23 & -0.25 & 0.52 & $\frac{F}{\rho g H_{\eta} d}$ & 2.2 & 1.3 & 1.6 & N/A & 0.15 & 1.57 & N/A \\
\hline & Dimensionless $H_{a}$ & $\frac{y-d}{H_{a}}$ & 3.17 & -0.66 & 1.30 & $\frac{F}{\rho g H_{a} d}$ & 5.4 & 3.1 & 4.0 & N/A & 0.37 & 3.92 & N/A \\
\hline
\end{tabular}
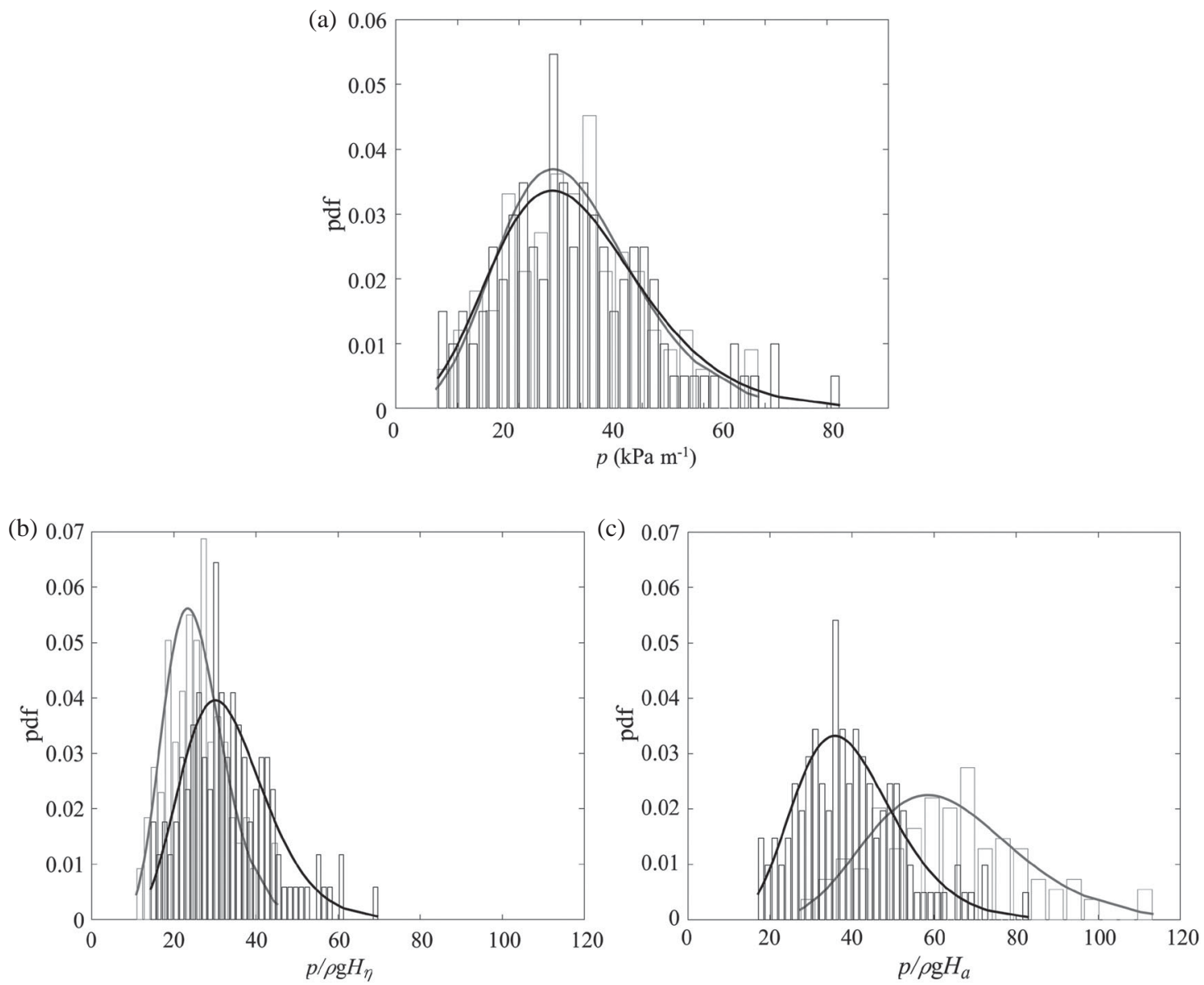

Figure 6 Theoretical Gamma pdf with histograms of the real datasets. Comparison of cnoidal (black) and linear (grey) wave generation theories. (a) Dimensional plot; (b) dimensionless plot in relation to $H_{\eta}$; (c) dimensionless plot in relation to $H_{a}$. Nearly breaking wave attack conditions. The sensors with the highest percentage of recorded maximum pressures are the PS6 for cnoidal and PS5 for linear

The dimensionless forces presented in Fig. $7 \mathrm{~b}$ and $7 \mathrm{c}$ were calculated by dividing the recorded force by $\rho g H d$, using $H_{\eta}$ and $H_{a}$.

Force results were fitted with a set of parametric probability distributions and the GEV function gave the best fit:

$$
\begin{aligned}
q_{F}= & \left(\frac{1}{\sigma}\right) \exp \left[-\left(1+r \frac{F-\mu}{\sigma}\right)^{-1 / r}\right] \\
& \times\left(1+r \frac{F-\mu}{\sigma}\right)^{-1-(1 / r)}
\end{aligned}
$$



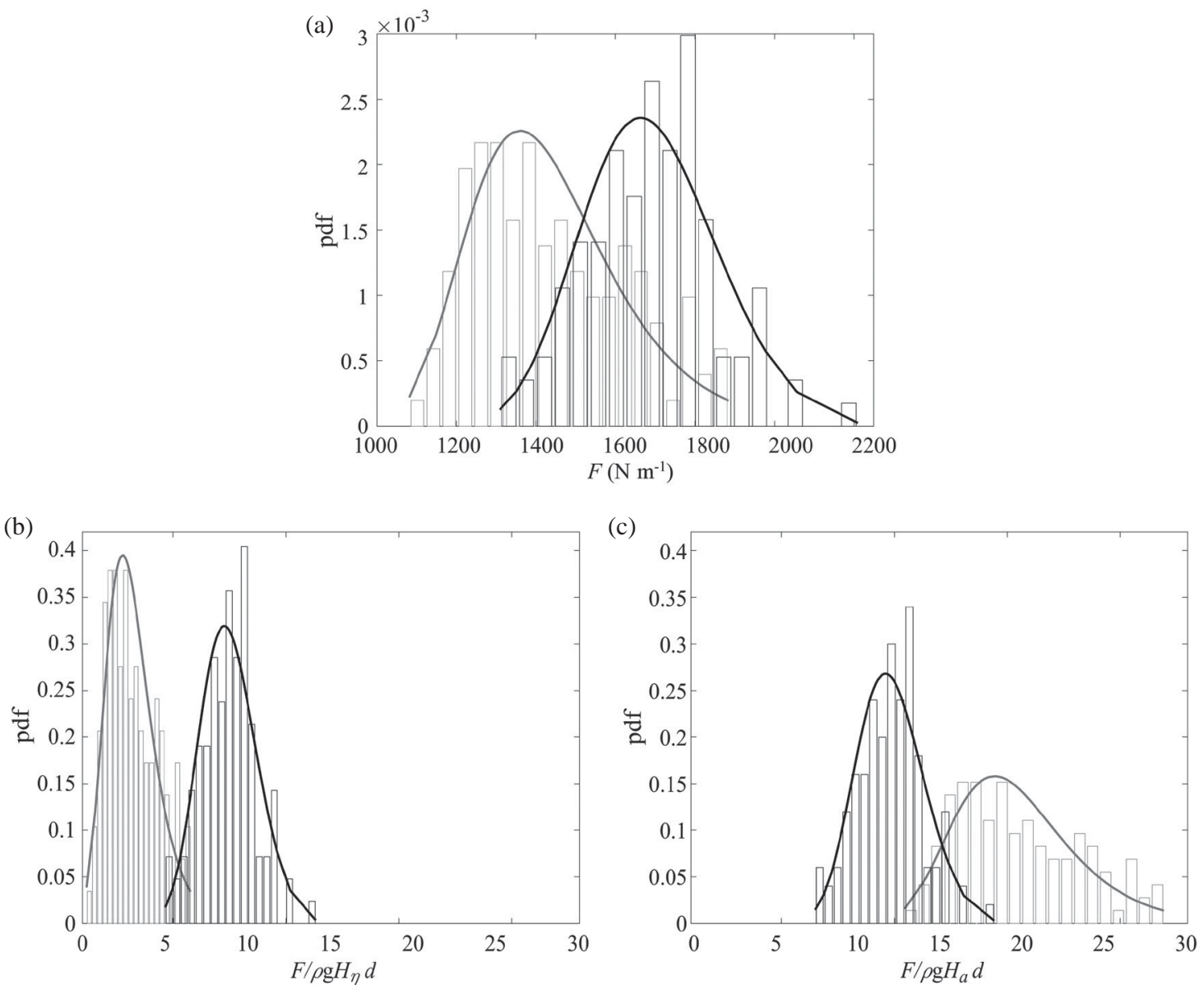

Figure 7 Theoretical GEV pdf with histograms of the real datasets. Comparison of cnoidal (black) and linear (grey) wave generation theories. (a) Dimensional plot; (b) dimensionless plot in relation to $H_{\eta}$; (c) dimensionless plot in relation to $H_{a}$. Nearly breaking wave attack conditions

where $q_{F}$ is the probability density function, $F$ is the force, $r$ is the shape parameter, $\sigma$ is the scale parameter, and $\mu$ is the location parameter. The results and $G E V$ parameters for the analysed force and application point datasets are summarized in Table 4.

\subsection{Broken wave attack loads}

Figure 8 shows vertical pressure distributions for broken wave attack. Dimensional (Fig. 8a) and dimensionless results (Fig. 8b and $8 \mathrm{c}$ ) are presented. In the case of cnoidal waves, the maximum pressure was recorded by PS2 in $42 \%$ of the cases (PS2 was the most probable point). Although PS2 recorded more maximum pressures events (42\%), PS3 recorded higher pressure values. This leads to higher mean maximum pressures at PS3 than PS2. At PS2, the maximum/minimum pressure ratio was $650 \%$, while the maximum/mean pressure ratio was $318 \%$. In the case of linear waves, the maximum pressure was recorded in $34 \%$ of the cases by PS2. For linear waves the maximum/minimum pressure ratio was $500 \%$, while the maximum/mean pressure ratio was $291 \%$. For broken waves, the Gamma distribution function provides a best fit to the maximum pressure recorded by PS2 for both the cnoidal and the linear cases (Eq. (6)). Table 5 summarizes the results for pressure induced by broken waves. The statistical distribution of the pressures (recorded by the sensors with the higher probability to register the maximum pressures) with the fitted Gamma distribution and the histograms of the two datasets are presented in Fig. 9.

Figure 10 shows the statistical distribution of the total force measured for broken waves. A $G E V$ distribution was selected because, as in the case of nearly breaking waves, this is the distribution that provides the best fit. The histograms of the two sets of data are presented, showing that in the case of cnoidal waves, pressure variability (Figs 9 and 10) is clearly higher than force variability. The maximum force was $166 \%$ of the minimum force and $140 \%$ of the most probable force value. Similar ratios were determined for linear waves, with a maximum recorded force of $177 \%$ and $137 \%$ of the minimum and the most probable values, respectively. Results for the forces induced by broken wave conditions are summarized in Table 6 .

\section{Discussion}

For nearly breaking cnoidal waves, a large range of pressures and forces was found. In this case, the maximum/minimum ratios for total force and maximum pressure were $168 \%$ and $482 \%$, respectively. These high ratios highlight the significant 

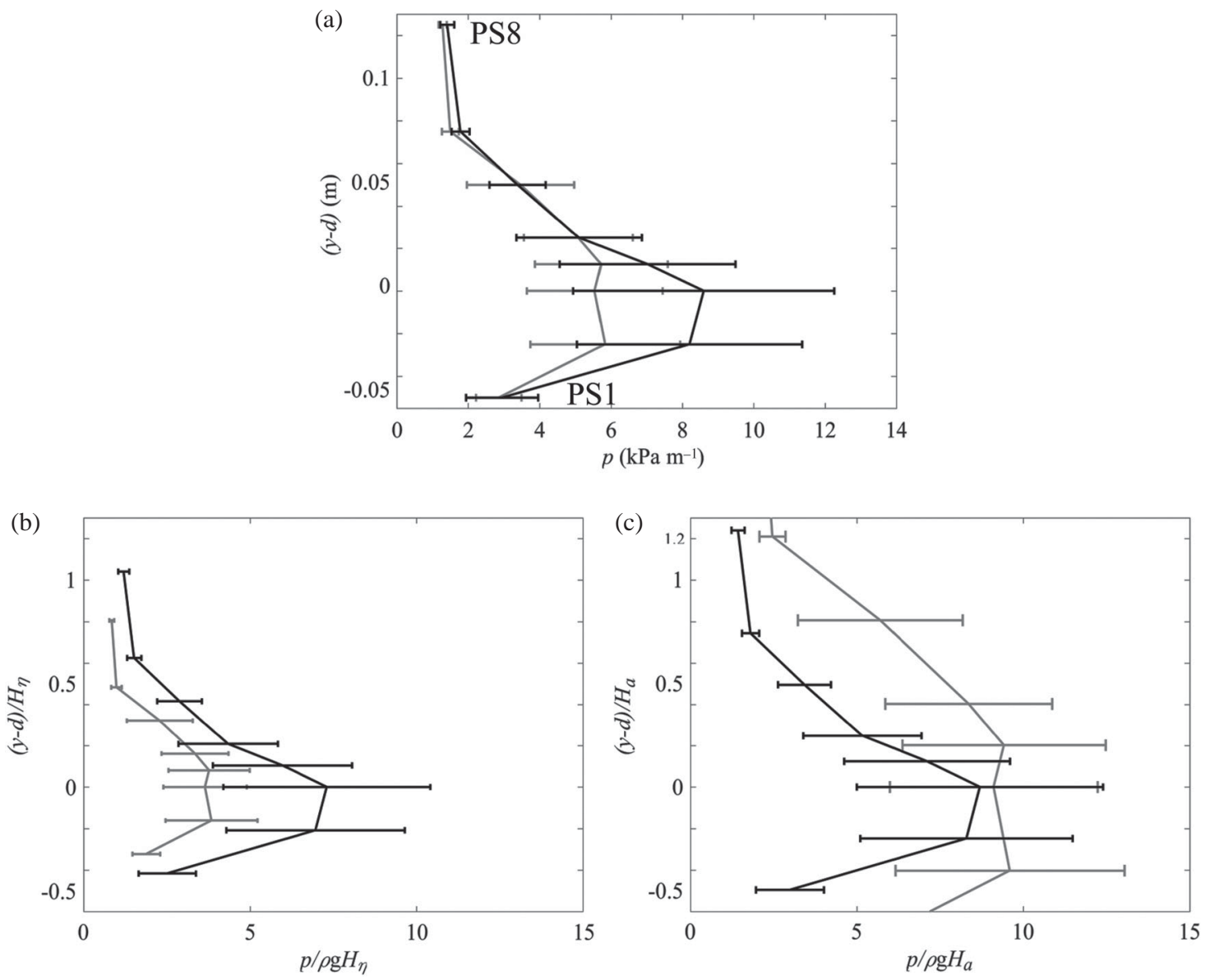

Figure 8 Comparison of vertical pressure distribution (means and standard deviations). Cnoidal (black) and linear (grey) wave generation theories. (a) Dimensional plot; (b) dimensionless plot in relation to $H_{\eta}$; (c) dimensionless plot in relation to $H_{a}$. Broken wave attack conditions

variability of the phenomena and the difficulties of predicting reasonable values during the design process of vertical breakwaters when considering wave impact conditions. We found that the measurements of forces and maximum pressures do not follow the same statistical distributions. GEV and Gamma are the three parameters distributions that best fit the set of data for forces and maximum pressures, respectively. Variability was also observed for the location of maximum pressure and force application point. However, these positions are always located between half and one wave amplitude above the SWL.

For broken cnoidal waves, the maximum/minimum ratio of total force was $166 \%$, similar to what was determined by nearly breaking cnoidal waves. However, this similarity was not observed for the maximum/minimum ratio of pressures. $G E V$ and Gamma were also the distributions that provide a best fit for the total force and the maximum pressure for broken waves. For the broken cnoidal waves, the application force point and maximum pressure point are located between a half wave amplitude below and above the SWL.

When carrying out experiments with linear wave generation, the variability observed for total force, force application point, and point of maximum pressure are similar to those found for nearly breaking and broken cnoidal waves. However, the force application point and the point of maximum pressure have a slightly lower position in the case of linear waves. In all four tested conditions, the highest variations in pressure measurements were found close to the pressure peak point.

For linear waves (with the presence of unwanted harmonics), the method for defining wave height can significantly affect the dimensionless analysis, a typical engineering artefact to extrapolate laboratory results to a prototype. When considering wave height as $H_{\eta}$, for cnoidal and linear waves, dimensionless and dimensional quantitative analysis of pressure and force are similar. However, when considering wave height as $H_{a}$, dimensionless and dimensional results are significantly different for linear waves. Differences of over $100 \%$ in magnitude and positions of forces and pressures were observed between the two dimensionless analyses used for the linear waves. Far from being a comprehensive study on the repeatability of wave generated impact forces/pressures, these results highlight the significant variability of these phenomena and the challenges in evaluating the correct design loads for vertical structures.

The high variability found in the study could be partly attributed to the spatial density of pressure transducers and to the randomness of wave breaking phenomena. A low spatial density of pressure transducers may hinder the detection of the 

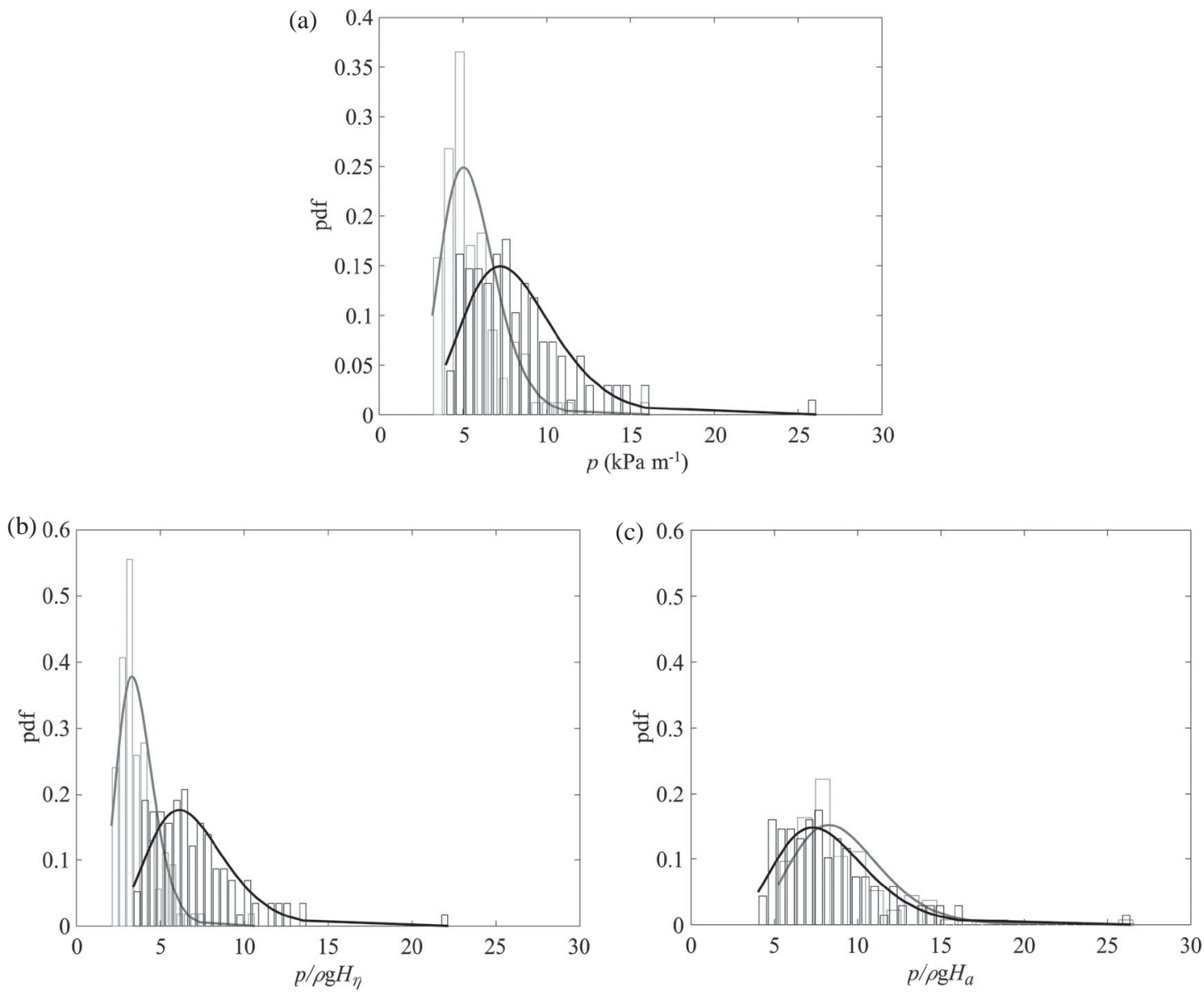

Figure 9 Theoretical Gamma pdf with histograms of the real datasets. Comparison of cnoidal (black) and linear (grey) wave generation theories. (a) Dimensional plot; (b) dimensionless plot in relation to $H_{\eta}$; (c) dimensionless plot in relation to $H_{a}$. Broken wave attack conditions. The sensors with the highest percentage of recorded maximum pressures are the one analysed (PS2 for both cnoidal and linear)

maximum pressure point. As shown by the results a higher variability is found around the maximum pressure point. In this regard, a denser sensor distribution should decrease the uncertainties on the characterization of pressures induced by wave impacts on vertical breakwaters. Moreover, the lower variability found for force measurements, obtained with load cells, confirms the effect of sensor distribution on pressure characterization. The mixing of air and water during wave breaking could be considered as an almost random phenomenon and therefore hardly repeatable. Because of that, the randomness of wave breaking phenomena can induce variability both in pressure and force measurements.

It is important to remember that both scale and laboratory effects can play a major role in the evaluation of such loads. The hydraulic tests presented here correspond to typical work scales (between 1/50 and 1/80), and therefore scale effects are to be expected. Moreover, it is also important to separate the variability induced by sensor distribution and wave breaking from the uncertainties generated by laboratory effects, such as the wave generation method and the accuracy of sensors. For example, it would be possible to extrapolate our results to irregular wave tests, considering the analysed regular wave as the maximum wave height in an irregular wave train. The probability of appearance of this type of loads is, in an irregular wave train, very low and a very small number of waves could be analysed (e.g. one to two waves) in comparison to the total number of generated waves (e.g. 1000 waves).

\section{Conclusions}

Test control and repeatability are essential to gain understanding in wave-induced pressure and forces on vertical structures. The analysis performed of impact conditions for nearly breaking and broken waves has allowed determination of total force variability, maximum pressure, and their corresponding locations. Based on four small-scale hydraulic experiments, probability distributions for regular wave-induced impact measurements (force and maximum pressure) are proposed. GEV and Gamma are the distributions that best fit the set of data for forces and maximum pressures, respectively. This proposal facilitates the setting up of hydraulic tests and selection of the appropriate wave conditions when designing vertical breakwaters. For all tested conditions, high variability in the measured pressure field and total force according to the random features of the studied phenomena were observed. The variability in the force 

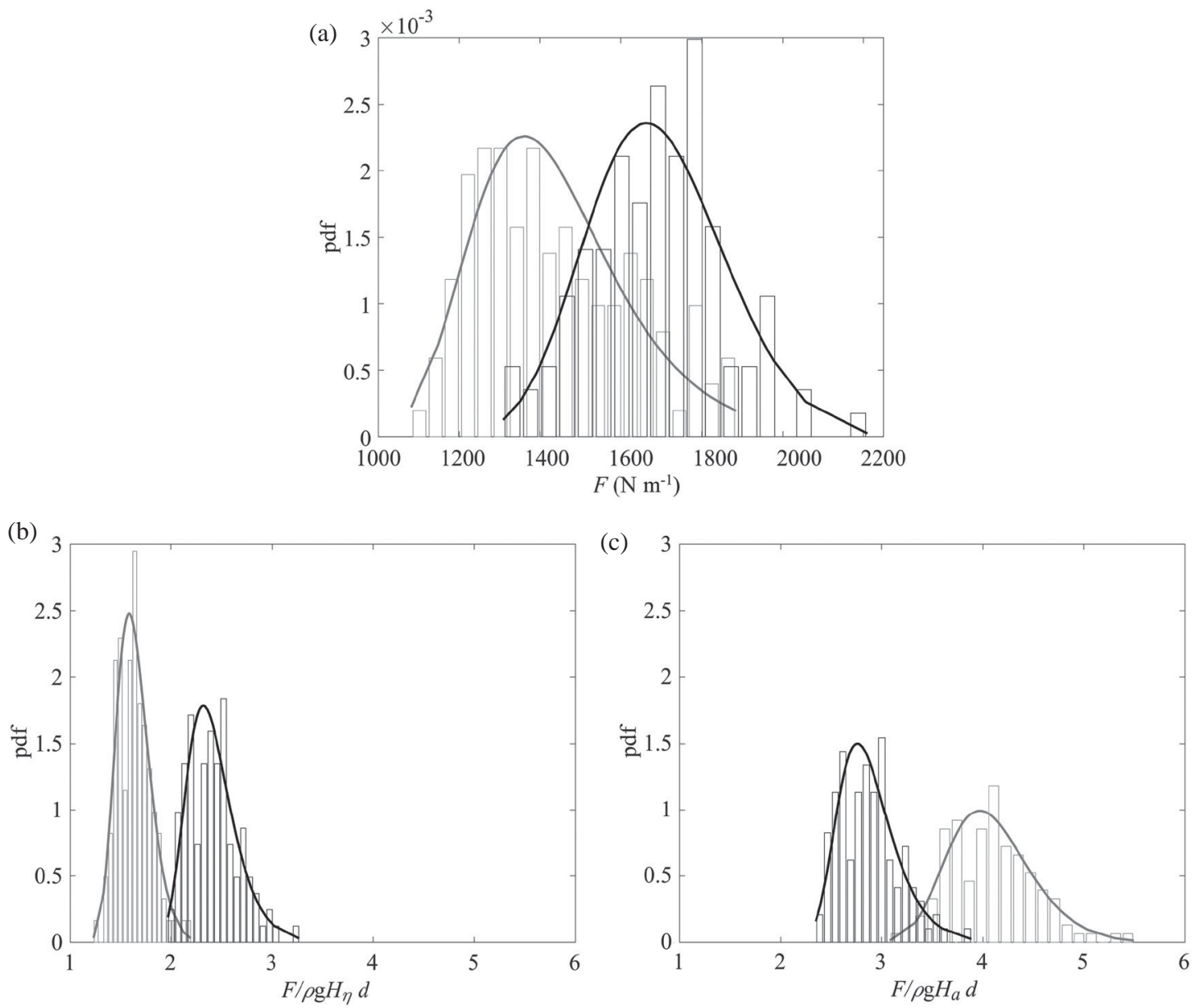

Figure 10 Theoretical GEV pdf with histograms of the real datasets. Comparison of cnoidal (black) and linear (grey) wave generation theories. (a) Dimensional plot; (b) dimensionless plot in relation to $H_{\eta}$; (c) dimensionless plot in relation to $H_{a}$. Broken wave attack conditions

was similar for the nearly breaking and broken waves. The maximum measured force was between 166 and $177 \%$ of the minimum measured force and higher variability was found for more local data such as the maximum pressure. In this case, the maximum measured value was between 430 and $650 \%$ of the minimum measured value. For the force application point and maximum pressure point, variability was higher for broken waves due to the inherent randomness of breaking induced turbulence.

Performing the proposed type of analysis (120 repetitions for each wave attack condition) for long series of irregular waves would be extremely time-consuming. However, with a small number of irregular wave tests repetitions and the suggested non-dimensional distributions, it would be possible to have an idea of the variability. Hydraulic test repeatability studies should lead in the future to a significant reduction of experimental times and improved quality of the resulting structural design.

\section{Acknowledgements}

The authors wish to thank the personnel of the CIEMLAB at the LIM-UPC BarcelonaTech for their assistance with the experiments.

\section{Funding}

This work was supported by Hydralab IV [grant number 261520]; Secretaria d'Universitats i Recerca del Dpt. d'Economia i Coneixement de la Generalitat de Catalunya [grant number 2014SGR1253]; Ministry of Education, Culture, and Sports, Spain [grant number AP-2010-4641]; Hydralab + [grant number GA654110].

\section{Notations}

$a \quad=$ wave amplitude (m)

$b=$ scale parameter of the Gamma pdf $(-)$

$d \quad=$ water depth at the toe of the structure (m)

$E_{R M S E}=$ root mean square error

$F \quad=$ force $\left(\mathrm{N} \mathrm{m}^{-1}\right)$

$G \quad=$ gravity acceleration $\left(\mathrm{m} \mathrm{s}^{-2}\right)$

$h=$ water depth in front of the paddle (m)

$H \quad=$ wave height $(\mathrm{m})$

$k=$ wave number $\left(\mathrm{m}^{-1}\right)$

$K(w)=$ complete elliptic integral of the first kind $(-)$

$L \quad=$ wave length $(\mathrm{m})$ 


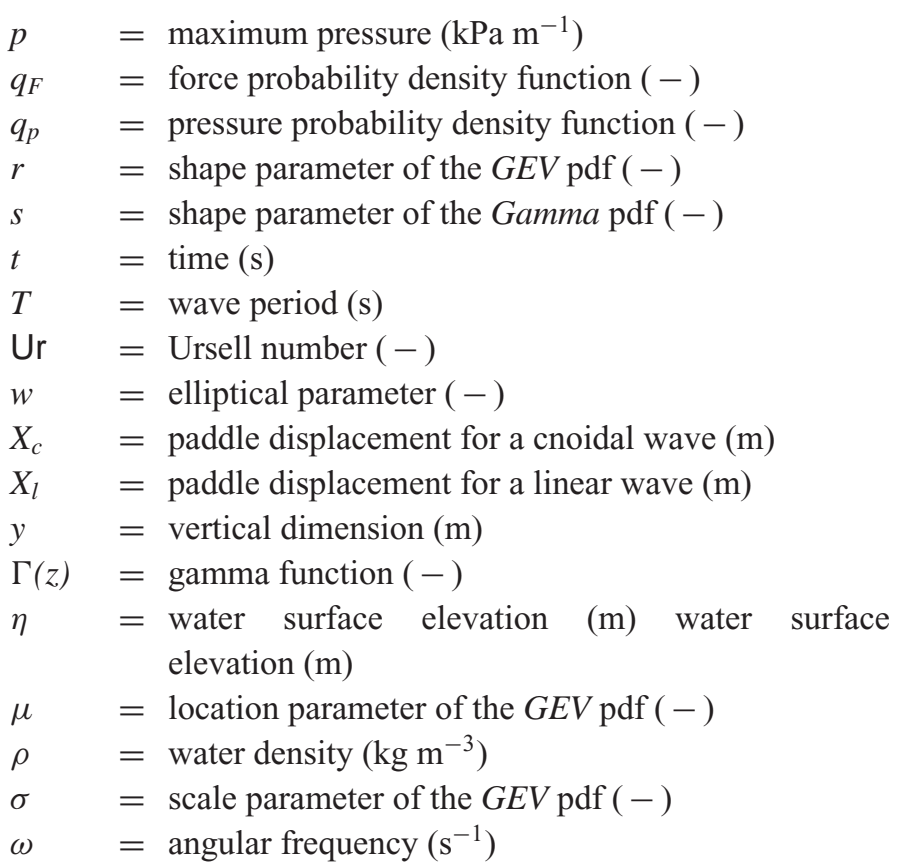

\section{ORCID}

Andrea Marzeddu (1) http://orcid.org/0000-0001-9515-7323

Tiago C. A. Oliveira (D) http://orcid.org/0000-0001-7040-7189

Francesc Xavier Gironella (D) http://orcid.org/0000-0002-8862-5704

Agustin SáNchez-Arcilla (D) http://orcid.org/0000-0002-3450-6697

\section{References}

Allsop, N. W. H., Kortenhaus, A., Oumeraci, H., \& McConnell, K. (1999). New design methods for wave loading on vertical breakwaters under pulsating and impact conditions. In I. J. Losada (Ed.), Coastal structures '99: Proceedings of an international conference, Santander, Spain, 7-10 June, 1999 (pp. 592-602). Rotterdam: Balkema.

Biésel, F., \& Suquet, F. (1951). Les appareils générateurs de houle en laboratoire. La Houille Blanche, 5, 723-737.

Bullock, G. N., Obhrai, C., Peregrine, D. H., \& Bredmose, H. (2007). Violent breaking wave impacts. Part 1: Results from large-scale regular wave tests on vertical and sloping walls. Coastal Engineering, 54(8), 602-617. doi:10.1016/j.coastaleng.2006.12.002

Cox, S. J., \& Cooker, M. J. (2001). The pressure impulse in a fluid saturated crack in a sea wall. Coastal Engineering, 42(3), 241-256. doi:10.1016/S0378-3839(00)00062-4

Cuomo, G., Allsop, N. W. H., Bruce, T., \& Pearson, J. (2010). Breaking wave loads at vertical seawalls and breakwaters. Coastal Engineering, 57(4), 424 439. doi:10.1016/ j.coastaleng.2009.11.005

Frostick, L. E., McLelland, S. J., \& Mercer, T. G. (2011). Users guide to physical modelling and experimentation: Experience of the HYDRALAB network. Boca Raton, FL: CRC Press.
Goda, Y. (1967). Travelling secondary wave crest in wave channels. Apendix to laboratory investigation on wave transmition over breakwaters Rep No Port Harbour Research Institute Japan, 13 SRC.

Goda, Y. (1974). New wave pressure formulae for composite breakwaters. In Proceedings of the 14th International Coastal Engineering Conference, 3, 1702-1720. Retrieved from https://icce-ojs-tamu.tdl.org/icce/index.php/icce/article/ view/2995

Goda, Y. (1985). Random seas and design of marine structures. Tokyo: University of Tokyo Press.

Goda, Y. (1997). Recurring evolution of water waves through nonresonant interactions. In B. L. Edge, J. M. Hemsley \& Y. Goda (Eds.), Ocean wave measurement and analysis: proceedings of the third international symposium WAVES 97: November 3-7, 1997 Ramada Plaza Resorct Viriginia Beach, Virginia, USA. Vol. 1. ASCE.

Goring, D. G. (1979). Tsunamis - the propagation of long waves onto a shelf. Pasadena, CA: California Institute of Technology.

Hofland, B., Lech Kaminski, M., \& Wolters, G. (2010). Large scale wave impacts on a vertical wall. Proceedings of 32nd conference on Coastal Engineering, Shanghai, China.

Hudspeth, R. T., \& Sulisz, W. (1991). Stokes drift in twodimensional wave flumes. Journal of Fluid Mechanics, 230, 209-229.

Hughes, S. A. (1993). Physical models and laboratory techniques in coastal engineering. Singapore: World Scientific.

Madsen, O. S. (1971). On the generation of long waves. Journal of Geophysical Research, 76, 8672-8683.

Marzeddu, A., Gironella, X., \& Sánchez-Arcilla, A. (2013). Impulsive wave loads on rigid structures, an experimental approach. Journal of Coastal Research, 1, 332-337. doi:10.2112/SI65-057.1

Marzeddu, A., Gironella, X., Sachez-Arcilla, A., \& Sutherland, J. (2014). Laboratory effects on measuring impact loads on rigid coastal structure. In 3rd IAHR Europe congress: book of proceedings, 2014, Porto - Portugal (pp. 1-9). IAHR.

Minikin, R. C. R. (1963). Winds, waves, and maritime structures: Studies in harbour making and in the protection of coasts. London: Griffin.

Morison, J. R., Crooke, R. C., \& Washington, D. C. (1953). The mechanics of deep and breaking waves: beach erosion board (Tech Memo No. 40 SRC).

Oliveira, T., Gironella, F., Sanchez-Arcilla, A., Sierra, J., \& Celigueta, M. (2009). Nonlinear regular wave generation in numerical and physical flumes. Journal of Coastal Research, 56, 1025-1029.

Oliveira, T. C. A., Sanchez-Arcilla, A., \& Gironella, X. (2012). Simulation of wave overtopping of maritime structures in a numerical wave flume. Journal of Applied Mathematics, 2012. doi:10.1155/2012/246146

Oliveira, T. C. A., Sachez-Arcilla, A., Gironella, F. X., \& Madsen, O. S. (2017). On the generation of regular long 
waves in numerical wave flumes based on the particle finite element method. Journal of Hydraulic Research. doi:10.1080/00221686.2016.1275047

Oumeraci, H. (1994). Review and analysis of vertical breakwater failures - lessons learned. Coastal Engineering, 22, 3-29. doi:10.1016/0378-3839(94)90046-9

Oumeraci, H., Allsop, N. W. H., De Groot, M., Crouch, R., Voortman, H., \& Vrijling, H. (2001). Probabilistic design tools for vertical breakwaters. Lisse: Swets \& Zeitlinger.

Schäffer, H. A. (1996). Second-order wavemaker theory for irregular waves. Ocean Engineering, 23(1), 47-88.

Stagonas, D., Marzeddu, A., Gironella, X., \& Sánchez-Arcilla, A. (2016). Measuring wave impact induced pressures with a pressure mapping system. Coastal Engineering, 112, 44-56.

Takahashi, S. (2002). Design of vertical breakwaters. Yokosuka: Port and Airport Research Institute.

Takahashi, S., Tanimoto, K., \& Shimosako, K. (1994). A proposal of impulsive pressure coefficient for design of composite breakwaters. In Proceedings of the international conference on hydro-technical engineering for port and harbor construction (pp. 489-504) Yokosuka: Port and Harbour Research Institute.

Zhang, H., \& Schäffer, H. A. (2007). Approximate stream function wavemaker theory for highly non-linear waves in wave flumes. Ocean Engineering, 34(8), 1290-1302. 